\title{
Article \\ Assessment on Agricultural Drought Vulnerability and Spatial Heterogeneity Study in China
}

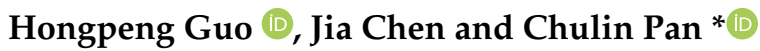 \\ College of Biological and Agricultural Engineering, Jilin University, 5988 Renmin Street, Changchun 130012, China; \\ ghp@jlu.edu.cn (H.G.); chenjia19@mails.jlu.edu.cn (J.C.) \\ * Correspondence: pancl@jlu.edu.cn
}

Citation: Guo, H.; Chen, J.; Pan, C. Assessment on Agricultural Drought Vulnerability and Spatial Heterogeneity Study in China. Int. J. Environ. Res. Public Health 2021, 18, 4449. https:// doi.org/10.3390/ijerph18094449

Academic Editors: Mikio Ishiwatari and Daisuke Sasaki

Received: 22 March 2021

Accepted: 20 April 2021

Published: 22 April 2021

Publisher's Note: MDPI stays neutral with regard to jurisdictional claims in published maps and institutional affiliations.

Copyright: (c) 2021 by the authors. Licensee MDPI, Basel, Switzerland. This article is an open access article distributed under the terms and conditions of the Creative Commons Attribution (CC BY) license (https:/ / creativecommons.org/licenses/by/ $4.0 /)$.

\begin{abstract}
Reducing drought vulnerability is a basis to achieve sustainable development in agriculture. The study focuses on agricultural drought vulnerability in China by selecting 12 indicators from two aspects: drought sensitivity and resilience to drought. In this study, the degree of agricultural drought vulnerability in China has been evaluated by entropy weight method and weighted comprehensive scoring method. The influencing factors have also been analyzed by a contribution model. The results show that: (1) From 1978 to 2018, agricultural drought vulnerability showed a decreasing trend in China with more less vulnerable to mildly vulnerable cities, and less highly vulnerable cities. At the same time, there is a trend where highly vulnerable cities have been converted to mildly vulnerable cities, whereas mildly vulnerable cities have been converted to less vulnerable cities. (2) This paper analyzes the influencing factors of agricultural drought vulnerability by dividing China into six geographic regions. It reveals that the contribution rate of resilience index is over $50 \%$ in the central, southern, and eastern parts of China, where agricultural drought vulnerability is relatively low. However, the contribution rate of sensitivity is $75 \%$ in the Southwest and Northwest region, where the agricultural drought vulnerability is relatively high. Among influencing factors, the multiple-crop index, the proportion of the rural population and the forest coverage rate have higher contribution rate. This study carries reference significance for understanding the vulnerability of agricultural drought in China and it provides measures for drought prevention and mitigation.
\end{abstract}

Keywords: agricultural drought vulnerability; spatial heterogeneity; entropy weight method; contribution model; China

\section{Introduction}

Drought occurs frequently in China and there has been a long history of these occurrences. From 206 BC to 1949, 1056 droughts occurred in China [1]. From 1971 to 2016, the average annual disaster rates of droughts in Heilongjiang, Jilin, Liaoning, and Inner Mongolia Autonomous Region were 19.4\%, 23.6\%, 25.4\% and 29.8\%, respectively. The average annual disaster rates of droughts in Anhui, Hebei, Henan, Jiangsu, and Shandong provinces were $11.5 \%, 20.4 \%, 16.2 \%, 8.9 \%$, and $18.3 \%$, respectively [2]. The Ministry of Emergency Management of the People's Republic of China has notified that from July to November of 2019, droughts had affected a total of 1174 thousand hectares of crops in Jiangxi and Anhui provinces, resulting in a direct economic loss of 8.8 billion yuan [3]. From January to April of 2020, 2.433 million people had been affected in 81 counties of 16 cities (prefectures) in Yunnan Province. A total of 662 thousand people had requested for life assistance due to droughts, and 534 thousand hectares of crops were affected, leading to direct economic loss of 1.41 billion yuan [4].

Drought is considered as a slow-moving natural disaster that causes severe damage to water resources and to agriculture [5]. The characteristics of drought include, but are not limited to, high frequency, long duration, and large area being influenced [6]. Agricultural drought is a crucial part of drought and it refers to the situation where 
agricultural production is sensitive and vulnerable to drought stress [7]. Agriculture utilizes natural resources directly and it is also a national anchoring industry. Agriculture is less capable of resisting and dealing with disasters. The resistance and handling capacity of agriculture to disasters is low so the adverse impact on agricultural production is most severe when drought occurs. In the same way, droughts can be intensified by poor land management [8]. Therefore, the situation of agriculture and the extent of drought affect each other. According to the Assessment Report of the AR5 Climate Change 2014: Impacts, Adaptation, and Vulnerability: Vulnerability encompasses a variety of concepts and elements including sensitivity or susceptibility to harm and lack of capacity to cope and adapt [9]. Taking the initiative via human activity is an effective way to alleviate the loss caused by a drought disaster [5]. So, measuring agricultural drought vulnerability is a prerequisite for targeting interventions to improve and sustain the agricultural performance of both irrigated and rain-fed agriculture [10].

Climate change has an increasing impact on production and people's lives. In recent years, the topic of vulnerability to agricultural drought has gradually become the focus and research hotspot of scholars around the world.

Yi (2010) evaluated the agricultural droughts in Dalian, China. Ten evaluation indexes such as irrigation index, population density and proportion of paddy areas were selected [11]. Yuan (2016) proposed a comprehensive index of regional drought vulnerability that includes exposure, sensitivity, and adaptability [12]. The establishment of evaluation indicators cannot be applied to all since it is highly subjective to regional characteristics. However, different indexing systems provide more research possibilities in the field of drought vulnerability.

Yan (2012), Pang et al. (2013), Farhangfar et al. (2015), Liu et al. (2015), and others conducted quantitative evaluation on drought vulnerability of maize and wheat and obtained the severity and spatial changes of crops at different growth stages [13-16]. Kim et al. (2018) used multivariate statistical analysis method to assess the agricultural vulnerability to droughts in South Korea and the results showed that the Chungchongnam-Do area was most vulnerable [17]. Lestari et al. (2018) used Arc GIS spatial overlay analysis to evaluate the agricultural drought vulnerability of Semarang Port City in India. The results showed that high vulnerability in six villages, medium vulnerability in seven villages, and low vulnerability in three villages [18]. Based on super sufficiency DEA, Huang et al. (2019) evaluated the agricultural drought vulnerability of Hetao Irrigation Area in Inner Mongolia and the results showed that the drought vulnerability in the eastern part of Hetao Irrigation Area was much higher than that in the western part [19]. Frischen et al. (2019) combined the result from spatial analysis of expert consultation and determined the drought vulnerability of Zimbabwe's agricultural system. The results showed that the country's drought vulnerability and the degree of impact vary greatly. The northern and southern part of Matabeleland, a province in southwestern part, have higher vulnerability level [20]. Das et al. (2019) used Savitzky and Golay filtering methods to study the agricultural drought situation and vulnerability in India from 1982 to 2015. Results showed that the vulnerability of drought will continue to decrease over time [21]. On the basis of selecting the research areas and constructing the evaluation index system, scholars have adopted different methods to evaluate the agricultural vulnerability to droughts. For example: Data envelopment analysis [22,23], analytic hierarchy process [24-28], principal component analysis [29,30], entropy weight method [31-33], etc. STATA [34,35], ArcGIS [36-38] and other software have also been used to construct an evaluation model for quantitative analysis.

Rojas et al. (2011) and Zhang et al. (2016) used remote sensing technology to monitor and predict agricultural drought $[39,40]$. Guo et al. (2016) proposed a new method (vulnerability surfaces) for assessing vulnerability quantitatively and continuously by including the environmental variable as an additional perspective on exposure and assessed global drought risk of maize based on these surfaces [41]. Chen et al. (2017) and Zeng et al. (2019) conducted drought risk assessment on Yunnan Province and Gansu Province re- 
spectively [42,43]. All the above studies have provided scientific methods for drought risk assessment and they have since enriched the assessment system for agricultural drought vulnerability.

Basing on a wide range of research areas and research methods, there exists the differences in the natural geographical environment, economic and social conditions, which has led to different influencing factors and various degrees of agricultural drought vulnerability. For example: Zarafshani et al. (2012) argued that the vulnerability of wheat farmers in the western part of Iran is mainly affected by economical, socio-cultural, psychological, technological, and infrastructural factors [44]. Wu et al. (2017) believed that the water shortage rate and irrigation level in the growing season were the main factors affecting the vulnerability level of regional agricultural drought [45]. Kamali et al. (2019) believed that the fertilization level is an important factor affecting the vulnerability of crop to drought in sub-Saharan Africa. Generally, countries with a higher food production index and better infrastructure perform better in terms of withstanding drought [46].

To sum up, there are two methods namely qualitative research and quantitative research on agricultural drought vulnerability. Existing research on agricultural drought vulnerability in China mainly focused on certain regions for quantitative research [7,14,32,37,45,47-51]. There were only a few studies on the overall assessment of agricultural drought vulnerability and among those the research objects, conclusions and countermeasures are limited.

Therefore, this paper focuses on the agricultural drought vulnerability in China. Based on literature review and relative theories, the paper first constructs the vulnerability evaluation index system of agricultural drought. Then the paper uses entropy weight method, weighted comprehensive scoring method as well as k-means clustering algorithm to evaluate and categorize the vulnerability of agricultural drought in China. Finally, using the contribution model to analyze the influencing factors and the degrees of agricultural drought vulnerability in China, this paper proposes countermeasures to reduce agricultural drought vulnerability in China. In one aspect, the paper carries theoretical value for enriching vulnerability research. It is also conducive to a better understanding of drought conditions and influencing factors in various regions of China. In another aspect, the empirical analysis provides the basis for the government to formulate corresponding policies, to reduce losses caused by disasters, and to promote the sustainable development of agriculture in China.

\section{Materials and Methods}

\subsection{Research Area Overview}

The People's Republic of China is located in East Asia and to the west coast of the Pacific Ocean. Liberated on 1 October 1949, China's capital city is Beijing and the provincial administrative divisions are divided into twenty-three provinces, five autonomous regions, four municipalities, and two special administrative regions. China's land area is about 9.6 million square kilometers. China is the world's second largest economy, the world's largest industrial country, and the world's largest agricultural country. At the end of 2019, the total population of mainland China was more than 1.4 billion.

The terrain is high in the West and low in the East. Mountains, plateaus, and hills account for estimated $67 \%$ of the land area, basins, and plains account for around $33 \%$ of the total land area. The climate condition is complex and diverse.

Looking at the situation and distribution of China's agricultural natural resources as a whole, the light and heat conditions are superior. However, there is a great regional differences of dry and wet conditions. The total amount of river runoff is large; however, the coordination and distribution of soil and water is not even. The absolute amount of land resources is large; however, the land occupied per capita is small. Agriculture still serves as the basic industry of China's national economy. 


\subsection{Establishment of Indicator System and Data Sources}

The establishment of evaluation index system is the prerequisite for evaluating agricultural drought vulnerability. Vulnerability is the root cause of drought disasters, which results from the interaction of natural environment and social economy system as well as the interactions of sensitivity and resilience in a certain space. Therefore, following the principles of science, comprehensiveness, pertinence, quantification, and availability of data [47], we select two first-level indicators, namely, sensitivity and resilience and 12 second-level indicators to conduct an evaluation on 31 provincial administrative units (except for Hong Kong, Macao, and Taiwan) in China to establish an indicator system (as shown in Table 1). The larger the indicator, the larger the vulnerability of agricultural drought. Hence, it is a positive indicator. On the contrary, it would be a negative indicator.

Sensitivity is the sum of all kinds of natural and social factors that would cause or aggravate drought and its impact on agricultural drought vulnerability is negative. That means the higher the sensitivity, the greater the vulnerability of agricultural drought. It includes agriculture in GDP proportion, multiple-crop index, rural population proportion, annual average temperature, annual sunshine duration, and annual precipitation.

Higher proportion of agriculture in GDP means that farmers rely heavily on agricultural income which is highly dependent on natural conditions. So the vulnerability of agricultural drought will increase. The higher the multiple-crop index, the more water the crop would need to grow. As a result, drought vulnerability will increase. The most severely impacted population at the time of drought is the agricultural population. Therefore, when the proportion of rural population increases, the degree of vulnerability will also increase. Moreover, higher the temperature and longer sunshine hours will lead to the increase of evaporation, and hence the agricultural drought vulnerability will increase together. Precipitation is the main factor affecting the growth of crops. The precipitation index can reflect the meteorological conditions of crops in this region and the impact of precipitation on vulnerability is negative.

Resilience refers to the ability of human society to prepare for, to respond to, and to recover from, disasters. It has a positive impact on agricultural drought vulnerability. That means the stronger the resilience, the lower the drought vulnerability. It includes forest coverage rate, net income per capita of rural residents, food production per capita, real GDP per capita, effective irrigation rate, and agricultural fertilizer per unit area.

The forest coverage rate reflects a country's (or region) actual level of forest resources and forestry possession. Net income per capita of rural residents reflects the group of people's economical ability to withstand and to resist drought. The higher the net income per capita of rural residents, the weaker the threats of agricultural drought. Food production per capita reflects the level of agricultural productivity. Real GDP per capita reflects the level of social and economic development. When the index is bigger, it means that the social and economic development level and the ability to withstand disasters is high. The effective irrigation rate reflects the degree of water conservancy and irrigation capacity. The increase of the amount of agricultural fertilizer per unit area is beneficial to enhance soil fertility, to improve soil structure and to increase the efficiency of land usage. The above indicators constitute the resilience of the agricultural system.

The agriculture in GDP proportion, the rural population proportion, the net income per capita of rural residents, the food production per capita, and the real GDP per capita affect the agricultural drought vulnerability from the economic and social perspectives. The multiple-crop index, the effective irrigation rate and the agricultural fertilizer per unit area affect the vulnerability of agricultural drought from the perspective of agricultural technology. The forest coverage rate, annual average temperature, annual sunshine duration, and precipitation affect the vulnerability of agriculture to drought from the perspective of natural conditions.

The indicator data in this paper comes from the website of the National Bureau of Statistics [52] and the China Meteorological Administration [53]. The annual precipitation, annual sunshine duration and annual average temperature are obtained from annual obser- 
vations from 613 weather stations nationwide from China Meteorological Administration data network. In addition to the forest coverage rate, net income per capita of rural residents and real GDP (Gross Domestic Product) per capita can be directly obtained, other indicators need to be calculated. The descriptive statistical results of the complete sample are shown in Table 2.

Table 1. Index system and source of China's agricultural drought vulnerability assessment.

\begin{tabular}{|c|c|c|}
\hline Indicators and Units & Calculation Formula & Source \\
\hline Agriculture in GDP proportion (\%) & Agricultural output value/GDP & {$[51,54]$} \\
\hline Multiple-crop index (\%) & $\begin{array}{l}\text { Cultivated area of crops/Total } \\
\text { cultivated area }\end{array}$ & [49] \\
\hline Rural population proportion (\%) & Rural population/Total population & {$[51,54]$} \\
\hline Annual average temperature $\left({ }^{\circ} \mathrm{C}\right)$ & $\begin{array}{c}\text { Annual average value of each } \\
\text { meteorological station }\end{array}$ & [32] \\
\hline Annual sunshine duration (h) & $\begin{array}{l}\text { Annual average value of each } \\
\text { meteorological station }\end{array}$ & [55] \\
\hline Annual precipitation $(\mathrm{mm})$ & $\begin{array}{l}\text { Annual average value of each } \\
\text { meteorological station }\end{array}$ & {$[51,54,56]$} \\
\hline The forest coverage rate $(\%)$ & Available directly & {$[56,57]$} \\
\hline $\begin{array}{l}\text { Net income per capita of rural } \\
\text { residents (yuan/per) }\end{array}$ & Available directly & {$[22,58,59]$} \\
\hline $\begin{array}{l}\text { Food production per } \\
\text { capita }(\mathrm{kg} / \text { per })\end{array}$ & Food production/Total population & [49] \\
\hline Real GDP per capita (yuan/per) & Available directly & {$[32,51,59]$} \\
\hline The effective irrigation rate (\%) & $\begin{array}{l}\text { Effective irrigation area/Total } \\
\text { cultivated area }\end{array}$ & {$[31,56]$} \\
\hline $\begin{array}{l}\text { Agricultural fertilizer per unit } \\
\text { area }\left(\text { ton } / \mathrm{hm}^{2}\right)\end{array}$ & $\begin{array}{c}\text { Amount of fertilizer used/Total } \\
\text { cultivated area }\end{array}$ & [32] \\
\hline
\end{tabular}

Table 2. Descriptive statistical results of samples.

\begin{tabular}{cccccc}
\hline Variable & Obs & Mean & Std. Dev. & Min & Max \\
\hline Agriculture in GDP proportion & 279 & 20.51542 & 12.75119 & 0.3193709 & 59.28663 \\
\hline Multiple-crop index & 279 & 1.371218 & 0.5034035 & 0.5117678 & 2.589842 \\
\hline Rural population proportion & 279 & 60.47917 & 20.75162 & 10.39337 & 91.76649 \\
\hline Annual average temperature & 279 & 13.00551 & 5.695829 & 0.5178571 & 25.18 \\
\hline Annual sunshine duration & 279 & 2136.61 & 481.6672 & 703.8 & 3075.392 \\
\hline Annual precipitation & 279 & 917.2576 & 495.0083 & 80.34242 & 2523 \\
\hline The forest coverage rate & 279 & 23.74077 & 16.91269 & 0.3 & 66.8 \\
\hline $\begin{array}{c}\text { Net income per capita of } \\
\text { rural residents }\end{array}$ & 279 & 4124.196 & 5357.99 & 100.93 & 30374.73 \\
\hline Food production per capita & 279 & 377.0782 & 225.9848 & 15.84958 & 1989.61 \\
\hline Real GDP per capita & 279 & $18,178.2$ & $25,786.47$ & 175 & 140,000 \\
\hline The effective irrigation rate & 279 & 0.5104425 & 0.229718 & 0.0719334 & 1 \\
\hline Agricultural fertilizer per unit area & 279 & 0.0388566 & 0.0252265 & 0.002069 & 0.1870795 \\
\hline
\end{tabular}




\subsection{Data Processing}

From Table 1, each indicator has different dimensions; hence, direct comparison is not possible. Therefore, it is necessary to carry out the dimensionless standardization of each indicator. The positive and negative indicators have different influence directions on agricultural drought vulnerability so the treatment methods should be different.

Suppose there are $k$ provinces, $n$ years and $m$ evaluation indicators; then $X_{\theta i j}$ represents the $j$ indicator value of province $i$ in year $\theta$. The normalized value after treatment is expressed as $S_{\theta i j}\left(0<S_{\theta i j}<1\right)$. $X_{\min }$ is the minimum value of the $j$ indicator and $X_{\max }$ is the maximum value of the $j$ indicator.

Positive indicator:

$$
S_{\theta i j}=\frac{X_{\theta i j}-X_{\min }}{X_{\max }-X_{\min }}
$$

Negative indicator:

$$
S_{\theta i j}=\frac{X_{\max }-X_{\theta i j}}{X_{\max }-X_{\min }}
$$

\subsection{Improved Entropy Weight Method}

There are two methods to determine the weight: subjective weight method and objective weight method. This paper chooses the entropy weighting method (one of the objective weighting methods) for indicator weighting, which overcomes the subjective arbitrariness of the subjective weighting method and makes the weighting more scientific. The improved entropy weighting method has the following methods and steps [60,61]:

Build the matrix $Y_{\theta i j}$ :

$$
Y_{\theta i j}=\frac{S_{\theta i j}}{\sum_{\theta} \sum_{i} S_{\theta i j}}
$$

Calculate indicator information entropy $e_{j}$ :

$$
e_{j}=-\frac{1}{\ln k n} \sum_{\theta} \sum_{i} Y_{i j} \ln \left(Y_{\theta i j}\right)
$$

Find indicator difference coefficient (redundancy) $g_{j}$ :

$$
g_{j}=1-e_{j}
$$

The weight of each indicator $w_{j}$ :

$$
W_{j}=\frac{g_{j}}{\sum_{j} g_{j}}
$$

\subsection{Vulnerability Assessment Model}

This paper chooses the weighted comprehensive scoring method and uses $V_{\theta i}$ to represent the degree of vulnerability. The improved vulnerability assessment model of agricultural drought in China is as follows:

$$
V_{\theta i}=\sum_{j}\left(W_{j} \times S_{\theta i j}\right)
$$

\subsection{K-Means Clustering Algorithm}

According to the above steps, to calculate the degree of vulnerability of the target year of China's agricultural drought in various regions and put them in ascending order. After that, to use k-means clustering algorithm in Stata to grade the vulnerability of China's agricultural drought disaster $[48,62]$. 
Algorithms usually use Euclidean distance to calculate the distance between samples. The calculation formula is as follows:

$$
d(x, y)=\sqrt{\sum_{i=1}^{n}\left(x_{i}-y_{i}\right)^{2}}
$$

Suppose the class center of the $k$ category is $c e n t e r_{k}$, then the formula of center ${ }_{k}$ is updated as follows:

$$
\text { center }_{k}=\frac{1}{\left|c_{k}\right|} \sum_{x_{i} \in c_{k}} x_{i}
$$

The clustering algorithm requires continuous iteration to re-classify and update center $_{k}$ value. Whenever the maximum number of iterations has been reached or the objective function is less than the threshold value, the iteration ends. The objective function is as follows:

$$
J=\sum_{k=1}^{k} \sum_{x_{i} \in c_{k}} d\left(x_{i}, \text { center }_{k}\right)
$$

\subsection{Contribution Model}

The main contributing factors of agricultural drought vulnerability in China are analyzed by contribution model. $R_{j}$ is the weight of the $j$ criterion level indicator; $C_{i j}$ is the contribution degree of the $j$ indicator factor to the vulnerability of the $i$ evaluation object; $U_{r}$ represents the contribution of the first level indicators to vulnerability; $F_{j}$ is the weight of single indicator to total target; $I_{i j}$ is the indicator membership degree (that is to say the proportion of Single factor indicator accounts for in vulnerability results. In the obstacle degree model, the indicator deviation degree is the difference between the individual index factor evaluation value and $100 \%$. Therefore, the factor membership in the contribution degree model is the single indicator factor evaluation value ratio $100 \%$ ) [32].

$$
\begin{gathered}
F_{j}=R_{j} \times W_{j} \\
I_{i j}=1-S_{\theta i j} \\
C_{i j}=\frac{F_{j} \times I_{i j}}{\sum_{j}\left(F_{j} \times I_{i j}\right)} \\
U_{r}=\sum C_{i j}
\end{gathered}
$$

\section{Results and Discussion}

\subsection{Agricultural Drought Vulnerability in China}

According to Formulas (1) and (2), after the data is being nondimensionalized and standardized, we use the calculation steps of the entropy weight method (Formulas (3)-(6)) to calculate the weight of each indicator, which is shown in Table 3.

It can be seen that, for the two first-class indicators, sensitivity index weight is 0.594 and resilience index weight is 0.406 . Among them, multiple-crop index, annual average temperature, the forest coverage rate, the effective irrigation rate, and agriculture in GDP proportion have higher weight of over 0.1. Since the weight of agricultural in GDP proportion is 0.099 , which is very close to 0.1 , we also put significant important over this index.

According to Formula (7), the agricultural drought vulnerability degree of each region in 1978, 1983, 1988, 1993, 1998, 2003, 2008, 2013, and 2018 have been calculated and shown in Table 4. 
Table 3. The weight of each indicator.

\begin{tabular}{cccc}
\hline $\begin{array}{c}\text { First-Level } \\
\text { Indicator }\end{array}$ & Weight & $\begin{array}{c}\text { Second-Level Indicatorand the } \\
\text { Direction of Influence }\end{array}$ & Weight \\
\hline & & A1. Agriculture in GDP proportion (+) & 0.099 \\
A2. Multiple-crop index (+) & 0.145 \\
A. Sensitivity & \multirow{2}{*}{0.594} & A3. Rural population proportion (+) & 0.071 \\
& & A4. Annual average temperature (+) & 0.106 \\
& & A5. Annual sunshine duration (+) & 0.081 \\
& A6. Annual precipitation (-) & 0.091 \\
\hline & B1. The forest coverage rate (-) & 0.102 \\
& & B2. Net income per capita of rural & 0.049 \\
B. Resilience & residents (-) & 0.049 \\
& \multirow{4}{*}{0.406} & B3. Food production per capita (-) & 0.045 \\
& & B4. Real GDP per capita (-) & 0.101 \\
& & B5. The effective irrigation rate (-) & 0.061 \\
\hline
\end{tabular}

Table 4. Vulnerability of agricultural drought in different provinces.

\begin{tabular}{|c|c|c|c|c|c|c|c|c|c|c|c|}
\hline \multirow{2}{*}{ Province } & \multicolumn{9}{|c|}{ Years } & \multirow{2}{*}{\multicolumn{2}{|c|}{ Level Sor }} \\
\hline & 1978 & 1983 & 1988 & נדנק & 1998 & 2003 & 2008 & 2013 & 2018 & & \\
\hline Shanghai & 0.492 & 0.476 & 0.491 & 0.438 & 0.419 & 0.378 & 0.426 & 0.469 & 0.303 & 0.432 & 1 \\
\hline Beijing & 0.505 & 0.517 & 0.492 & 0.513 & 0.427 & 0.417 & 0.399 & 0.408 & 0.541 & 0.469 & 2 \\
\hline Zhejiang & 0.579 & 0.553 & 0.407 & 0.528 & 0.502 & 0.443 & 0.419 & 0.417 & 0.375 & 0.469 & 3 \\
\hline Guangdong & 0.499 & 0.476 & 0.501 & 0.474 & 0.545 & 0.500 & 0.446 & 0.464 & 0.345 & 0.472 & 4 \\
\hline Fujian & 0.549 & 0.520 & 0.524 & 0.521 & 0.485 & 0.434 & 0.467 & 0.444 & 0.349 & 0.477 & 5 \\
\hline Tianjin & 0.514 & 0.536 & 0.508 & 0.522 & 0.493 & 0.434 & 0.460 & 0.457 & 0.483 & 0.490 & 6 \\
\hline Jilin & 0.503 & 0.491 & 0.493 & 0.508 & 0.515 & 0.487 & 0.510 & 0.492 & 0.535 & 0.504 & 7 \\
\hline Heilongjiang & 0.485 & 0.500 & 0.493 & 0.501 & 0.499 & 0.479 & 0.526 & 0.493 & 0.562 & 0.504 & 8 \\
\hline Liaoning & 0.520 & 0.520 & 0.534 & 0.535 & 0.509 & 0.494 & 0.521 & 0.509 & 0.582 & 0.525 & 9 \\
\hline $\mathrm{Ji}$ & 0.593 & 0.612 & 0.609 & 0.558 & 0.526 & 0.442 & 0.524 & 0.530 & 0.392 & 0.532 & 10 \\
\hline Hun & 0.526 & 0.527 & 0.554 & 0.539 & 0.576 & 0.508 & 0.592 & 0.585 & 0.398 & 0.534 & 11 \\
\hline & 0.598 & 0.571 & 0.598 & 0.591 & 0.547 & 0.496 & 0.577 & 0.538 & 0.422 & 0.549 & 12 \\
\hline Shaanxi & 0.590 & 0.581 & 0.572 & 0.570 & 0.560 & 0.529 & 0.586 & 0.573 & 0.545 & 0.567 & 13 \\
\hline Hubei & 0.607 & 0.587 & 0.630 & 0.610 & 0.585 & 0.512 & 0.585 & 0.574 & 0.463 & 0.573 & 14 \\
\hline Sichuan & 0.562 & 0.581 & 0.568 & 0.572 & 0.650 & 0.572 & 0.635 & 0.616 & 0.516 & 0.586 & 15 \\
\hline $\mathrm{Gu}$ & 0.613 & 0.636 & 0.645 & 0.638 & 0.587 & 0.573 & 0.574 & 0.581 & 0.507 & 0.595 & 16 \\
\hline Shandong & 0.663 & 0.662 & 0.667 & 0.622 & 0.587 & 0.528 & 0.567 & 0.578 & 0.495 & 0.597 & 17 \\
\hline $\begin{array}{c}\text { Inner } \\
\text { Mongolia }\end{array}$ & 0.635 & 0.638 & 0.634 & 0.615 & 0.613 & 0.568 & 0.558 & 0.548 & 0.579 & 0.599 & 18 \\
\hline Shanxi & 0.623 & 0.628 & 0.615 & 0.621 & 0.607 & 0.551 & 0.582 & 0.580 & 0.598 & 0.601 & 19 \\
\hline Hebei & 0.639 & 0.662 & 0.640 & 0.632 & 0.592 & 0.556 & 0.589 & 0.593 & 0.543 & 0.605 & 20 \\
\hline & 0.699 & 0.6 & 0.681 & 0.630 & 0.612 & 0.533 & 0.603 & 0.585 & 0.462 & 0.606 & 1 \\
\hline Yunnan & 0.608 & 0.614 & 0.616 & 0.631 & 0.614 & 0.588 & 0.607 & 0.642 & 0.577 & 0.611 & 22 \\
\hline Xinji & 0.634 & 0.633 & 0.612 & 0.587 & 0.581 & 0.599 & 0.634 & 0.633 & 0.601 & 0.613 & 23 \\
\hline Chongqing & 0.674 & 0.666 & 0.675 & 0.681 & 0.616 & 0.618 & 0.583 & 0.588 & 0.484 & 0.620 & 24 \\
\hline Qinghai & 0.583 & 0.621 & 0.614 & 0.618 & 0.636 & 0.598 & 0.619 & 0.648 & 0.649 & 0.621 & 25 \\
\hline Henan & 0.690 & 0.681 & 0.710 & 0.669 & 0.653 & 0.543 & 0.676 & 0.622 & 0.483 & 0.636 & 26 \\
\hline Hainan & 0.657 & 0.710 & 0.683 & 0.649 & 0.705 & 0.606 & 0.584 & 0.576 & 0.586 & 0.640 & 27 \\
\hline & 0.615 & 0.674 & 0.681 & 0.678 & 0.647 & 0.606 & 0.597 & 0.610 & 0.694 & 0.645 & 28 \\
\hline Guizh & 0.634 & 0.659 & 0.699 & 0.659 & 0.734 & 0.593 & 0.619 & 0.641 & 0.583 & 0.647 & 29 \\
\hline Ning & 0.656 & 0.686 & 0.679 & 0.669 & 0.648 & 0.615 & 0.644 & 0.622 & 0.643 & 0.651 & 30 \\
\hline Gansu & 0.629 & 0.660 & 0.645 & 0.667 & 0.687 & 0.643 & 0.674 & 0.681 & 0.735 & 0.669 & 31 \\
\hline
\end{tabular}


It can be noticed that from 1978 to 2018, the vulnerability of agricultural drought in China has decreased year by year. Agricultural drought vulnerability in Gansu, Ningxia, Guizhou, and Tibet is relatively high with an average value of more than 0.648 . Agricultural drought vulnerability in Shanghai, Beijing, and Zhejiang is low with the average value less than 0.47 .

\subsubsection{Classification of Agricultural Drought Vulnerability}

In order to accurately classify China's agricultural drought vulnerability, according to Formulas (8)-(10) by using k-means clustering algorithm in Stata, the China Agricultural Drought Vulnerability Index (ADVI) is divided into four ranges between 0 to 1 and they are shown in Table 5.

Table 5. Classification of agricultural drought vulnerability.

\begin{tabular}{cc}
\hline Grade & Range \\
\hline Low vulnerability & $(0,0.463)$ \\
Mild vulnerability & $(0.463,0.552)$ \\
Middle vulnerability & $(0.552,0.628)$ \\
High vulnerability & $(0.628,1)$ \\
\hline
\end{tabular}

\subsubsection{Spatial Distribution and Evolution}

According to the classification of agricultural drought vulnerability in Table 5, in order to express the results more clearly, this study uses ArcGIS to display the research results. The assessment results of agricultural drought vulnerability in China are shown in Figure 1a-i.

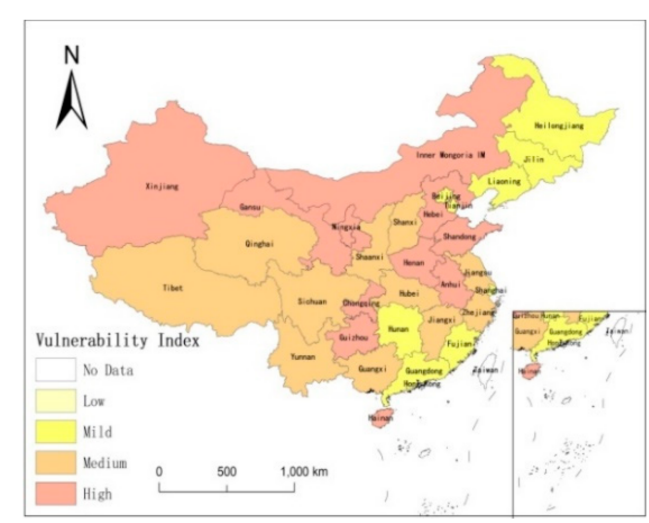

(a) 1978

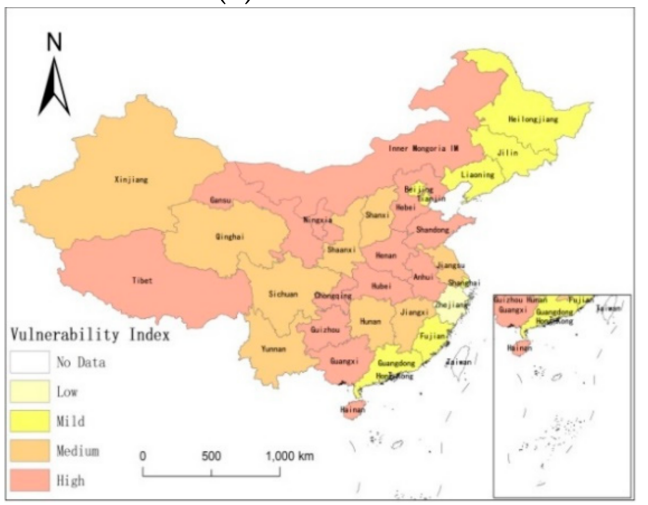

(c) 1988

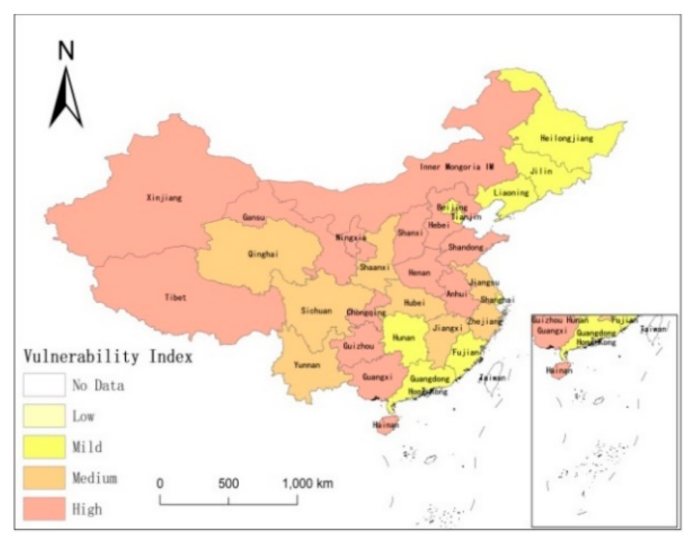

(b) 1983

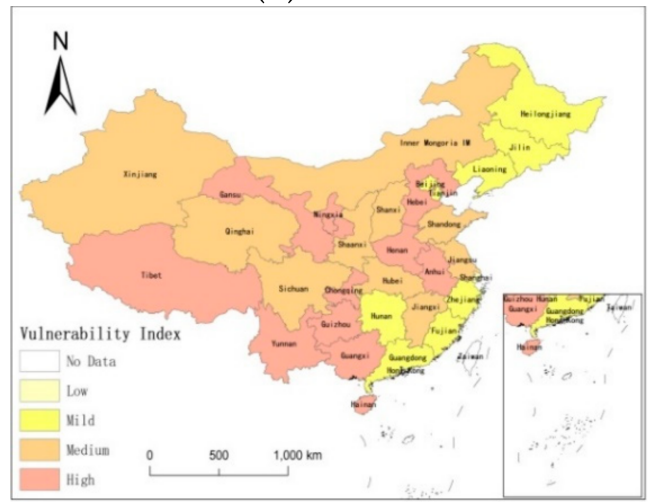

(d) 1993

Figure 1. Cont. 


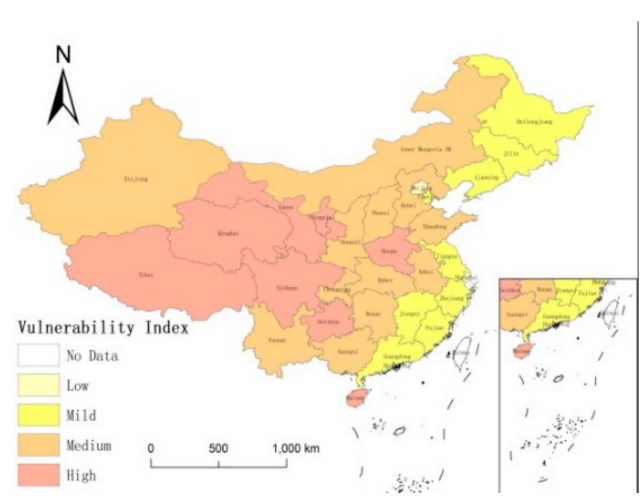

(e) 1998

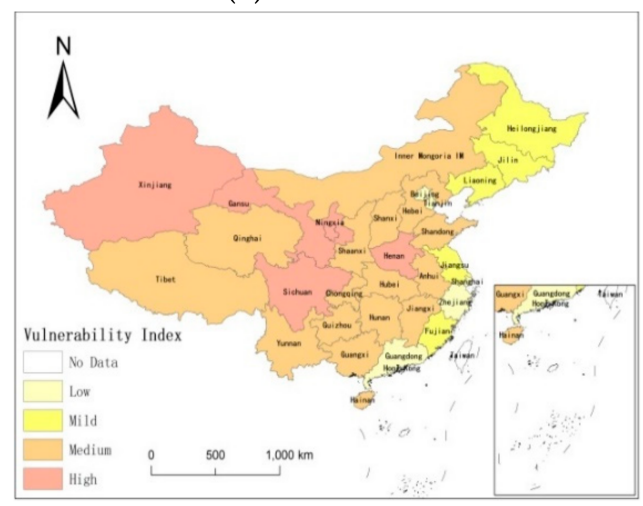

(g) 2008

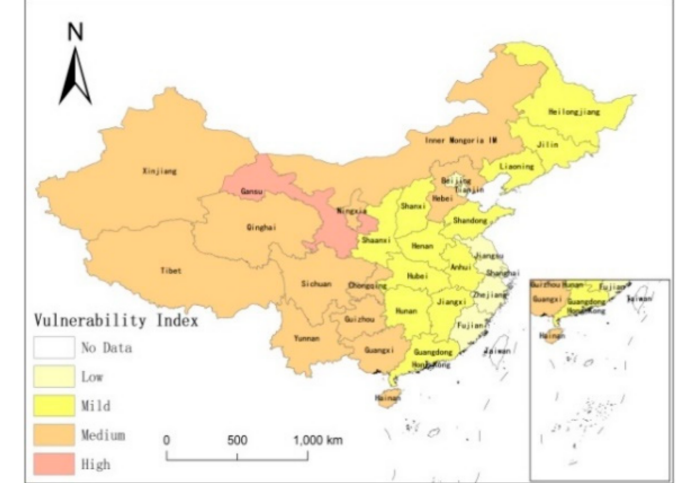

(f) 2003

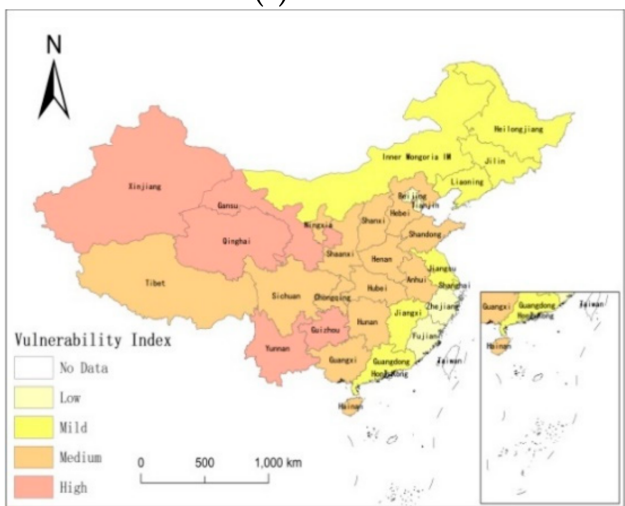

(h) 2013

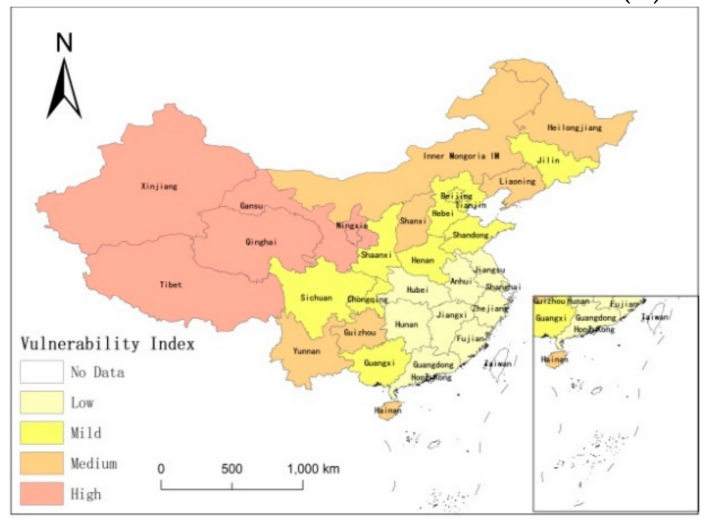

(i) 2018

Figure 1. Spatiotemporal evolution of agricultural drought vulnerability in China (a-i).

It can be seen that the vulnerability of agricultural drought in China has changed significantly over time: from 1978 to 2018, the number of provinces and cities in low and mild vulnerability state has been increasing.

From 1978 to 2018, the spatial distribution pattern of agricultural drought vulnerability in China was obvious:

(1) The overall agricultural drought vulnerability in China is 0.569 , which is at a moderate fragile level. This is in line with the characteristics of frequent droughts and serious losses in China [63-65].

(2) Highly vulnerability level: $(0.628<$ ADVI $<1)$ Over time, the number of cities in highly vulnerable areas has decreased, which mainly included Xizang, Guizhou, Ningxia, Gansu, etc. Among them, Gansu, Ningxia have higher vulnerability to drought, which is consistent with the research results of other scholars [59,66]. Firstly, most of these areas have complex terrain conditions and less precipitation. Drought 
is their main natural feature. Secondly, the region is less developed compared with other regions and real GDP per capita is low while agriculture in GDP proportion and rural population proportion is high. It means that farmers are highly dependent on agricultural and natural conditions. With high sensitivity and weak resilience when drought occurs, the number of highly vulnerable provinces and cities are inevitably high.

(3) Middle vulnerability level: $(0.552<$ ADVI $<0.628)$ The number of provinces and cities in this region is stable and it accounts for nearly half of the total number of provinces and cities in China and most of them are concentrated in Central China. It included Inner Mongolia, Sichuan, Hebei, Anhui, etc. Most of them are important grain production bases in China and major agricultural provinces. Agriculture in GDP proportion, multiple-crop index and rural population proportion are high. It reflects that the region has a strong dependence on agriculture with high land utilization rate and heavy water demand.

(4) Low and mild vulnerability level: $(0<$ ADVI < 0.552$)$ Although there has seen a small fluctuation in the number of slightly vulnerable provinces and cities, the overall trend shows a stable and marginal increase. This is consistent with the research results of some scholars $[22,67]$. The provinces and cities in this region such as Shanghai, Zhejiang, Beijing, and Tianjin have a high level of economic development. Their high real GDP per capita gives them better response ability and post disaster recovery ability when disasters occur. At the same time, those provinces and cities tend to have a small agricultural planting area multiple-crop index, agriculture in GDP proportion and rural population proportion are also low. When we turn to those provinces and cities in the Northeast China like Heilongjiang, Jilin, and Liaoning, their land is sparsely populated and the food production per capita is high. They also have high latitude, low average temperature, and less evaporation. The annual sunshine duration is long and the crops normally harvest once a year. With lower multiple-crop index, the water demand is lesser and the sensitivity of disaster is weak.

\subsection{Analysis on the Influencing Factors of Agricultural Drought Vulnerability in China}

3.2.1. Factor Contribution Analysis of First Level Index

According to the research results of agricultural drought vulnerability assessment in China, it can be noticed that the distribution of provinces and cities in different vulnerability levels has certain regional characteristics. Therefore, this paper studies the influencing factors of vulnerability in different regions. It adopts China's six geographic regions: North China, Northeast China, Northwest China, East China, Central and Southern China, and Southwest China. According to the Formulas (11)-(14), the contribution of sensitivity and resilience is shown in Figures 2 and 3.

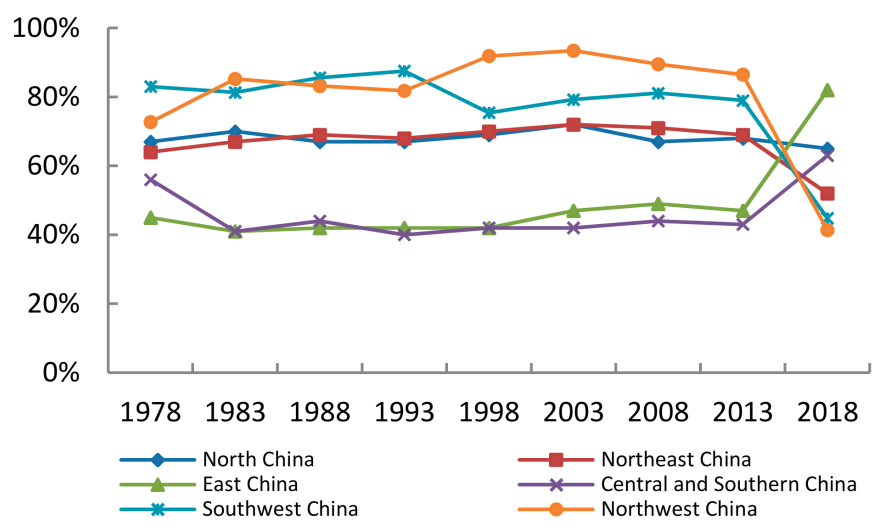

Figure 2. Changes in the contribution of sensitivity indicators. 


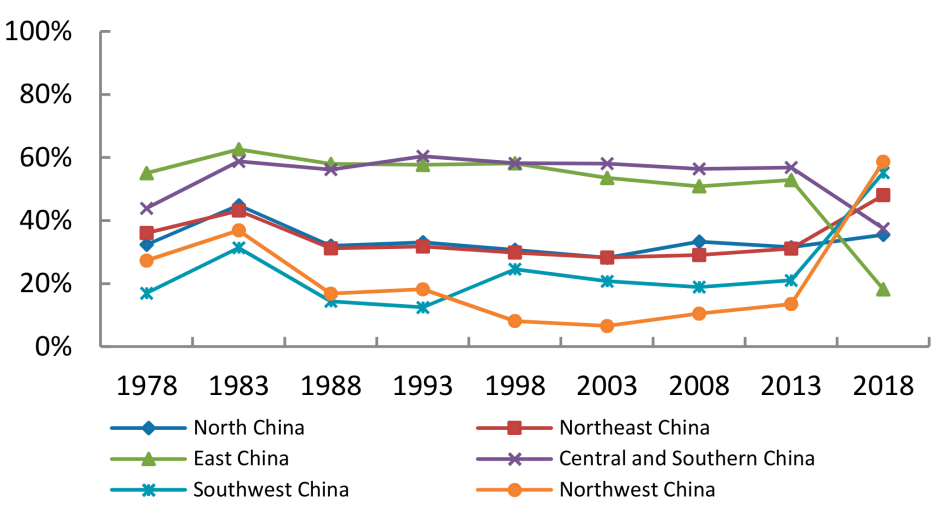

Figure 3. Changes in the contribution of resilience indicators.

As shown in Figure 2, looking at the trends as a whole, during the period of 1978-2013, the contribution of sensitivity indexes in different regions was relatively stable. From 2013 to 2018, except for North China, the contribution ratio of sensitivity indicators in other regions changed dramatically.

The contribution of sensitivity indicators in Northeast China, Northwest China, and Southwest China have declined. Possible reasons are as follows: agriculture in GDP proportion, multiple-crop index, and annual sunshine duration has decreased drastically while annual precipitation has increased significantly. Farmers in these regions have become less dependent on agricultural income. Lower land use has reduced water demand, and hence there is less evaporation.

The contribution of sensitivity indexes in East China and Central South have increased significantly. Possible reasons are as follows: agriculture in GDP proportion and multiplecrop index have increased while land use in the region has improved and water demand has increased.

As shown in Figure 3, looking at the trends as a whole, during the period of 1978-2013, the contribution of resilience indexes in different regions was relatively stable. From 2013 to 2018, except for North China, the contribution ratio of resilience indicators in other regions changed dramatically.

The contribution of resilience indicators in Northeast China, Northwest China, and Southwest China have increased. I think the possible reasons are as follows: the contribution of forest coverage rate, food production per capita, and agricultural fertilizer per unit area have increased while net income per capita of rural residents has declined. The region is less dependent on agriculture, needs to improve its ability to conserve water, and is less able to cope with disasters and recover from disasters.

The contribution of resilience indicators in East China, Central China, and South China have decreased evidently. Possible reasons are as follows: the forest coverage rate, the effective irrigation rate and agricultural fertilizer per unit area have increased. The region's ability to conserve water is better, so the recovery capacity after the disaster is improved.

On the whole, the contribution of resilience in East China, Central, and Southern China is more than $50 \%$, which is greater than the contribution of sensitivity. Cities in the central and southern region: the Yellow River valley passes through Henan, and the Yangtze River valley passes through Hubei and Hunan. Guangxi, Guangdong, and Hainan are adjacent to the sea. Therefore, the relative abundance of water resources and the contribution of sensitivity indicators are less. East China includes Shanghai, Jiangsu, Zhejiang, Anhui, Fujian, Jiangxi, and Shandong. These several provinces and cities are adjacent to the sea, or within the territory of the river flow through, and the level of economic development is at the forefront of China. Therefore, the contribution degree of resilience index is relatively high.

Northwest China, Northeast China, North China, and Southwest China have higher sensitivity contributions than that of resilience. The sensitivity contribution of the South- 
west China and Northwest China is as high as 75\%. Desert is widespread in the northwest and annual precipitation about 200-400 mm. Deep inland and blocking the arrival of moist air. Northeast China is an important grain production base with a large area of cultivated land. Compared with the coastal areas, its economic development level is not high.

\subsubsection{Factor Contribution Analysis of Secondary Index}

Select the top four indicators of contribution among the 12 indicators and the calculated results are shown in Table 6.

Table 6. The top four indicators and contribution of agricultural drought vulnerability in different regions.

\begin{tabular}{|c|c|c|c|c|c|c|c|c|c|c|c|c|}
\hline \multirow[t]{2}{*}{$\begin{array}{l}\text { Regions } \\
\text { Years }\end{array}$} & \multicolumn{2}{|c|}{ North China } & \multicolumn{2}{|c|}{ Northeast China } & \multicolumn{2}{|c|}{ East China } & \multicolumn{2}{|c|}{$\begin{array}{c}\text { Central and } \\
\text { Southern China }\end{array}$} & \multicolumn{2}{|c|}{$\begin{array}{l}\text { Southwest } \\
\text { China }\end{array}$} & \multicolumn{2}{|c|}{$\begin{array}{l}\text { Northwest } \\
\text { China }\end{array}$} \\
\hline & A3 & A1 & $\mathrm{A} 2$ & A3 & A5 & B4 & A5 & A6 & A5 & A3 & $\mathrm{A} 2$ & A4 \\
\hline \multirow[t]{3}{*}{1978} & 19.14 & 17.33 & 17.69 & 15.33 & 16.78 & 13.51 & 25.73 & 19.51 & 26.02 & 17.52 & 30.17 & 24.05 \\
\hline & $\mathrm{A} 2$ & B4 & A4 & A1 & B5 & A6 & B6 & B5 & A2 & A6 & A1 & B6 \\
\hline & 15.34 & 13.98 & 15.03 & 12.26 & 13.39 & 11.64 & 12.95 & 11.22 & 16.48 & 12.99 & 18.47 & 10.72 \\
\hline \multirow{4}{*}{1983} & A1 & A6 & $\mathrm{A} 2$ & A3 & A5 & B5 & A5 & B6 & A5 & A6 & $\mathrm{A} 2$ & A6 \\
\hline & 16.04 & 15.46 & 16.01 & 14.30 & 21.32 & 15.00 & 32.92 & 17.32 & 32.83 & 12.67 & 26.31 & 22.12 \\
\hline & A2 & A3 & A4 & B1 & B4 & A1 & B1 & B5 & A3 & A2 & A4 & A1 \\
\hline & 14.50 & 13.29 & 13.60 & 10.88 & 14.01 & 10.93 & 14.13 & 13.64 & 12.60 & 11.74 & 20.80 & 12.16 \\
\hline \multirow{4}{*}{1988} & A1 & A3 & A2 & A3 & A5 & B2 & A5 & B6 & A5 & A3 & A2 & A6 \\
\hline & 15.47 & 15.17 & 16.48 & 14.72 & 15.04 & 13.80 & 29.65 & 16.36 & 33.60 & 19.91 & 21.14 & 19.18 \\
\hline & A2 & B4 & A4 & A1 & B5 & B4 & B1 & A3 & A2 & A4 & A4 & A3 \\
\hline & 13.92 & 12.48 & 14.00 & 13.28 & 13.03 & 12.94 & 14.00 & 12.46 & 11.73 & 11.01 & 17.64 & 14.32 \\
\hline \multirow{4}{*}{1993} & A1 & A2 & A2 & A4 & A5 & B4 & A5 & B1 & A5 & A3 & A2 & A6 \\
\hline & 15.51 & 15.33 & 16.44 & 13.97 & 20.21 & 14.89 & 27.93 & 15.28 & 31.28 & 26.59 & 21.74 & 19.60 \\
\hline & A6 & B4 & A3 & A1 & $\mathrm{A} 1$ & B2 & B6 & & A6 & A4 & A4 & A1 \\
\hline & 13.82 & 12.51 & 12.92 & 11.21 & 13.02 & 12.97 & 15.26 & В5 10.7 & 10.58 & 10.54 & 18.43 & 10.98 \\
\hline \multirow{4}{*}{1998} & A1 & $\mathrm{A} 2$ & $\mathrm{~A} 2$ & A3 & A5 & A1 & A5 & B1 & A5 & A4 & A2 & A6 \\
\hline & 14.71 & 14.60 & 17.43 & 15.57 & 19.33 & 13.14 & 29.65 & 17.82 & 40.25 & 14.11 & 24.87 & 21.12 \\
\hline & A3 & A6 & A4 & B1 & B2 & B1 & B6 & B5 & A6 & A2 & A4 & $\mathrm{A} 3$ \\
\hline & 12.84 & 12.15 & 14.81 & 11.85 & 11.48 & 10.88 & 15.27 & 10.36 & 11.14 & 9.93 & 19.22 & 18.46 \\
\hline \multirow{4}{*}{2003} & A3 & $\mathrm{A} 2$ & $\mathrm{~A} 2$ & A3 & A5 & B4 & A5 & B1 & A5 & B1 & $\mathrm{A} 2$ & A6 \\
\hline & 15.25 & 13.85 & 16.24 & 15.17 & 16.10 & 12.34 & 31.60 & 21.12 & 36.68 & 13.65 & 28.07 & 22.37 \\
\hline & A1 & A6 & $\mathrm{A} 4$ & B1 & A1 & B2 & B6 & $\mathrm{A} 3$ & A6 & A2 & A4 & $\mathrm{A} 3$ \\
\hline & 13.80 & 12.06 & 15.03 & 12.02 & 12.30 & 12.34 & 15.45 & 10.32 & 13.37 & 16.61 & 20.78 & 11.94 \\
\hline \multirow{4}{*}{2008} & A3 & A1 & A2 & A4 & A5 & A3 & A5 & B1 & A5 & $\mathrm{A} 2$ & A2 & A6 \\
\hline & 15.20 & 13.76 & 18.76 & 15.94 & 16.13 & 13.64 & 31.02 & 21.16 & 32.99 & 21.60 & 27.46 & 23.87 \\
\hline & A2 & A6 & A3 & A6 & A1 & B2 & B6 & A3 & B1 & A6 & A4 & A1 \\
\hline & 11.95 & 11.87 & 14.19 & 11.90 & 11.56 & 11.23 & 16.46 & 11.95 & 14.10 & 11.82 & 22.45 & 9.96 \\
\hline \multirow{4}{*}{2013} & A3 & A1 & $\mathrm{A} 2$ & A4 & A3 & A5 & A5 & B1 & A5 & $\mathrm{A} 2$ & $\mathrm{~A} 2$ & A6 \\
\hline & 15.30 & 13.85 & 19.32 & 16.41 & 15.52 & 14.56 & 31.32 & 20.26 & 28.93 & 19.64 & 26.18 & 25.94 \\
\hline & A6 & A2 & A3 & B1 & A1 & B2 & B6 & $\mathrm{A} 3$ & B1 & A6 & A4 & A3 \\
\hline & 13.85 & 11.94 & 12.89 & 11.16 & 13.52 & 11.92 & 15.76 & 11.84 & 15.33 & 14.52 & 20.60 & 7.40 \\
\hline \multirow{4}{*}{2018} & A3 & A1 & A4 & A6 & $\mathrm{A} 2$ & A5 & A5 & $\mathrm{A} 2$ & A5 & B4 & A6 & A4 \\
\hline & 18.97 & 17.17 & 19.15 & 14.24 & 21.93 & 19.19 & 25.82 & 25.37 & 21.36 & 13.26 & 15.32 & 13.55 \\
\hline & A6 & $\mathrm{A} 2$ & B4 & $\mathrm{A} 3$ & A3 & A1 & B4 & $\mathrm{A} 3$ & B2 & A6 & B1 & B4 \\
\hline & 15.76 & 12.10 & 12.87 & 12.78 & 18.00 & 17.68 & 12.02 & 10.09 & 10.30 & 10.14 & 13.06 & 11.94 \\
\hline
\end{tabular}

On the whole, referring to the calculation results above, it can be noticed that the contribution factors of agricultural drought vulnerability in China mainly focus on sensitivity. Among them, A2 (multiple-crop index) and A3 (rural population proportion) are more important. It shows that these two indicators have a greater impact on the vulnerability of agricultural drought. We should sustainably reduce the land utilization rate, reduce the water demand, strengthen the vocational skills training of rural residents, supervise and 
protect the legitimate rights and interests of migrant workers, and promote the transfer of rural population to cities. Hence, the proportion of rural population can be effectively reduced, and the vulnerability of agricultural drought can also be mitigated.

Among the indexes of resilience, B1 (the forest coverage rate) and B4 (real GDP per capita) are more important. According to the data from the Ninth National Forest Resources Inventory, China's forest coverage rate is still lower than the world average level. Strengthening afforestation is highly effective for soil and water conservation, hence reducing water evaporation and improving the forest coverage rate. The adverse impact from drought can also be reduced significantly. Similarly, the higher the real GDP per capita, the easier the recovery would be after droughts. The GDP per capita China is still relatively low in the worldwide spectrum, although China's total domestic GDP ranks No. 1 in the world.

The factor with the least contribution is B3 (Food production per capita). China has a large planting area of crops with high and stable grain yield, so it has little impact on agricultural drought vulnerability.

\section{Conclusions, Limitations, and Future Research}

The paper uses entropy weight method, weighted comprehensive scoring method as well as k-means clustering algorithm to calculate and classify the vulnerability degree of agricultural drought. ArcGIS was used to show the spatial and temporal changes of agricultural drought vulnerability in China, then, using the contribution model to analyze the influencing factors and the degrees of agricultural drought vulnerability in China, the results show that:

(1) From 1978 to 2018, the vulnerability of agriculture to drought has been reduced and the numbers of China's highly vulnerable cities have declined. During the same time, there has been a trend appeared that high vulnerability cities have converted to the middle-level vulnerability cities while middle-level vulnerability cities have converted to mild-level or low-level vulnerability cities. The vulnerability towards agricultural drought disasters in China was generally at the middle and mild level in most regions while the vulnerability in Northwest China and Southwest China were more severe.

(2) China's agricultural drought vulnerability is mainly affected by sensitivity factors, among which multiple-crop index and the proportion of rural population have a higher contribution compared with other indicators. For resilience index, forest coverage rate and real GDP per capita carry a more important role.

In the data collection process of this paper, partially due to the wide time span selected, there is a lack of data from early years. Therefore, those crucial indicators that can be easily obtained with clean data have been selected for evaluation. Imperfection still exists although these selected indicators can truly reflect the vulnerability characteristics of agricultural drought in China. In the future, we will do some comparative studies on different evaluation methods to further optimize the research results.

Author Contributions: Conceptualization, H.G. and C.P.; Data curation, C.P. and J.C.; Formal analysis, H.G.; Funding acquisition, H.G.; Investigation, C.P. and J.C.; Methodology, H.G. and J.C.; Project administration H.G.; Resources, H.G.; Software, H.G. and J.C.; Supervision, C.P.; Validation, H.G. and J.C.; Visualization, H.G.; Writing—original draft H.G. and J.C.; Writing-review and editing, J.C. and C.P. All authors have read and agreed to the published version of the manuscript.

Funding: Social Science Fund Project of Jilin Province, China, grant No.2018BS33; MOE (Ministry of Education in China) Project of Humanities and Social Sciences, grant/award No.18YJC630128; Social Science Fund Project of "the 13th Five-Year" of Education Department of Jilin Province, China, grant No. JJKH20190736SK; and Jilin Province Education Planning Project, China, grant No. JJKH20190243SK.

Institutional Review Board Statement: Not applicable. 
Informed Consent Statement: Not applicable.

Data Availability Statement: Publicly available datasets were analyzed in this study. This data can be found here: China Statistical Yearbook (http:/ / www.stats.gov.cn/english/Statisticaldata/ AnnualData/, accessed on 17 July 2020), China Rural Statistical Yearbook (https:/ / data.cnki.net/ trade/yearbook/single/n2019120190?z=z009, accessed on 23 July 2020), China Meteorological Administration Data Network (https: / / data.cma.cn/, accessed on 28 July 2020).

Conflicts of Interest: The authors declare no conflict of interests.

\section{References}

1. Sun, G.Z. Analysis of Natural disasters in China disaster and disaster reduction countermeasures. Bull. Chin. Acad. Sci. 1990, 01, 37-39.

2. Tian, Z.H.; Li, X.X. Drought Change Cycle in China's Major Grain Producing Areas Based On Disaster Situation. J. Catastrophol. 2020, 35, 40-45.

3. Duan, M. Ministry of Emergency Management: The Direct Economic Losses Caused by Natural Disasters in November Totaled 2.29 Billion Yuan. Available online: https://www.mem.gov.cn/xw/mtxx/201912/t20191205_341963.shtml (accessed on 15 December 2019).

4. Li, Z.Y. The Emergency Management Department Released the National Natural Disaster Situation in April 2020. Available online: https:/ / www.mem.gov.cn/xw /bndt/202005/t20200508_352280.shtml (accessed on 8 May 2020).

5. Zarafshani, K.; Sharafi, L.; Azadi, H.; Van Passel, S. Vulnerability Assessment Models to Drought: Toward a Conceptual Framework. Sustainability 2016, 8, 588. [CrossRef]

6. Wu, J.S.; Lin, X.; Wang, M.J.; Peng, J. Assessing Agricultural Drought Vulnerability by a VSD Model: A Case Study in Yunnan Province, China. Sustainability 2017, 9, 918. [CrossRef]

7. Guan, Y.H.; Zheng, F.L.; Zhang, P.; Qin, C. Spatial and temporal changes of meteorological disasters in China during 1950-2013. Nat. Hazards 2015, 75, 2607-2623. [CrossRef]

8. IPCC. Climate Change and Land; Special Report; Intergovernmental Panel on Climate Change: Geneva, Switzerland, 2019.

9. IPCC. AR5 Climate Change 2014: Impacts, Adaptation and Vulnerability; Intergovernmental Panel on Climate Change: Geneva, Switzerland, 2014.

10. Murthy, C.S.; Yadav, M.; Ahamed, J.M.; Laxman, B.; Prawasi, R.; Sai, M.V.R.S.; Hooda, R.S. A study on agricultural drought vulnerability at disaggregated level in a highly irrigated and intensely cropped state of India. Environ. Monit. Assess. 2015, 187, 140. [CrossRef] [PubMed]

11. Yi, J.M. Risk Assessment of Agricultural Drought in Dalian; Liaoning Normal University: Dalian, China, 2010.

12. Yuan, X.C. Climate Change Risk Assessement: Modeling and Applications; Beijing Institute of Technology: Beijing, China, 2016.

13. Yan, L. A Study on Dynamic Risk Assessment of Maize Drought Disaster in Northwestern Liaoning Province. Master's Thesis, Northeast Normal University, Changchun, China, 2012.

14. Pang, Z.Y.; Dong, S.N.; Zhang, J.Q.; Tong, Z.J.; Liu, X.P.; Sun, Z.Y. Evaluation and regionalization of maize vulnerability to drought disaster in Western Jilin Province based on CERES-Maize model. Chin. J. Eco Agric. 2014, 22, 705-712.

15. Farhangfar, S.; Bannayan, M.; Khazaei, H.R.; Baygi, M.M. Vulnerability assessment of wheat and maize production affected by drought and climate change. Int. J. Disaster Risk Reduct. 2015, 13, 37-51. [CrossRef]

16. Liu, X.J.; Zhang, J.Q.; Ma, D.L. The Study of Vulnerability Assessment on Maize Drought in the Northwest of Liaoning Province Based on Modis. Chin. J. Agric. Resour. Reg. Plan. 2016, 37, 44-49.

17. Kim, S.-M.; Kang, M.-S.; Jang, M.-W. Assessment of agricultural drought vulnerability to climate change at a municipal level in South Korea. Paddy Water Environ. 2018, 16, 699-714. [CrossRef]

18. Lestari, D.R.; Pigawati, B. Drought disaster vulnerability mapping of agricultural sector in Bringin District, Semarang Regency. IOP Conf. Ser. Earth Environ. Sci. 2018, 123, 012031. [CrossRef]

19. Huang, J.; Fu, P.; Tong, J.P.; She, J.W.; Zhang, J.X. Evaluating the vulnerability of agricultural drought in Hetao Irrigation Area of Inner Mongolia Based on super efficiency DEA. IOP Conf. Ser. Earth Environ. Sci. 2019, 330, 032020. [CrossRef]

20. Frischen, J.; Meza, I.; Rupp, D.; Wietler, K.; Hagenlocher, M. Drought Risk to Agricultural Systems in Zimbabwe: A Spatial Analysis of Hazard, Exposure, and Vulnerability. Sustainability 2020, 12, 752. [CrossRef]

21. Das, R.; Das, P.K.; Bandyopadhyay, S.; Raj, U. Trends And Vulnerability Assessment of Meteorological and Agricultural Drought Conditions over Indian Region Using Time-Series (1982-2015) Satellite Data. Int. Arch. Photogramm. Remote Sens. Spat. Inf. Sci. 2019, XLII-3, 453-459. [CrossRef]

22. Pei, H.; Wang, X.Y.; Fang, S.F. Study on Temporal-spatial Evolution of Agricultural Drought Vulnerability of China Based on DEA Model. J. Catastrophol. 2015, 30, 64-69.

23. Yuan, X.-C.; Wang, Q.; Wang, K.; Wang, B.; Jin, J.-L.; Wei, Y.-M. China's regional vulnerability to drought and its mitigation strategies under climate change: Data envelopment analysis and analytic hierarchy process integrated approach. Mitig. Adapt. Strateg. Global Chang. 2015, 20, 341-359. [CrossRef]

24. Ekrami, M.; Marj, A.F.; Barkhordari, J.; Dashtakian, K. Drought vulnerability mapping using AHP method in arid and semiarid areas: A case study for Taft Township, Yazd Province, Iran. Environ. Earth Sci. 2016, 75, 1039. [CrossRef] 
25. Lakshmi, S.V.; Rakshith, R.K.; Manoj, N. Drought vulnerability assessment and mapping using Multi-Criteria decision making (MCDM) and application of Analytic Hierarchy process (AHP) for Namakkal District, Tamilnadu, India. Mater. Today Proc. 2020, 43, 1592-1599.

26. Sik, M.Y.; Ho, N.W.; Gi, J.M.; Joong, K.H.; Ku, K.; Chul, L.J.; Hyun, H.T.; Kwangya, L. Evaluation of Regional Drought Vulnerability Assessment Based on Agricultural Water and Reservoirs. J. Korean Soc. Agric. Eng. 2020, 62, 97-109.

27. Wu, H.; Qian, H.; Chen, J.; Huo, C. Assessment of Agricultural Drought Vulnerability in the Guanzhong Plain, China. Water Resour. Manag. 2017, 31, 1557-1574. [CrossRef]

28. Zagade, N.D.; Umrikar, B.N. Drought severity modeling of upper Bhima river basin, western India, using GIS-AHP tools for effective mitigation and resource management. Nat. Hazards 2020, 105, 1165-1188. [CrossRef]

29. Balaganesh, G.; Malhotra, R.; Sendhil, R.; Sirohi, S.; Maiti, S.; Ponnusamy, K.; Sharma, A.K. Development of composite vulnerability index and district level mapping of climate change induced drought in Tamil Nadu, India. Ecol. Indic. 2020, 113, 106197. [CrossRef]

30. Liu, L.-F.; Shi, Y.; Jin, J.-L.; Xiao, Z.-C.; Deng, M.-R. Assessment on Drought Vulnerability in Subtropical Rice Areas-A Case of Hengyang Basin in China. In Proceedings of the 2013 International Conference on Advanced in Earth Sciences (ICAES 2013), Pilani, India, 21-23 September 2013; Volume 8.

31. Guo, Y.; Wang, R.; Tong, Z.J.; Liu, X.P.; Zhang, J.Q. Dynamic Evaluation and Regionalization of Maize Drought Vulnerability in the Midwest of Jilin Province. Sustainability 2019, 11, 4234. [CrossRef]

32. $\mathrm{Xu}, \mathrm{H}$. Assessment of agricultural drought vulnerability and identification of influencing factors based on the entropy weight method. Agric. Res. Arid Areas 2016, 34, 198-205.

33. Yu, Z.L.; Yang, X.J.; Shi, Y.Z. Evaluation of Urban Vulnerability to Drought in Guanzhong Area. Resour. Sci. 2012, 34, 581-588.

34. Liu, Q.J.; Wei, M.D.; Li, Z.N.; Hu, Y.K. Study on vulnerability measurement and its differences of farmers in typically deep poverty-stricken regions based on household micro-data survey in Northwest Inland Arid Regions of China. J. Chin. Agric. Mech. 2020, 41, 215-223.

35. Addis, E. Agro-ecosystems' Vulnerability to Climate Change in Drought Prone Areas of Northeastern Ethiopia. J. Nat. Sci. Res. 2017, 7, 21-41.

36. Alamdarloo, E.H.; Khosravi, H.; Nasabpour, S.; Gholami, A. Assessment of drought hazard, vulnerability and risk in Iran using GIS techniques. J. Arid Land 2020, 12, 984-1000. [CrossRef]

37. Huang, L.; Yang, P.; Ren, S. The Vulnerability Assessment Method for Beijing Agricultural Drought. In Computer and Computing Technologies in Agriculture VII; Springer: Berlin/Heidelberg, Germany, 2014; p. 12.

38. Jain, V.K.; Pandey, R.P.; Jain, M.K. Spatio-temporal assessment of vulnerability to drought. Nat. Hazards 2015, 76, 443-469. [CrossRef]

39. Rojas, O.; Vrieling, A.; Rembold, F. Assessing drought probability for agricultural areas in Africa with coarse resolution remote sensing imagery. Remote Sens. Environ. 2010, 115, 343-352. [CrossRef]

40. Zhang, J.; Mu, Q.Z.; Huang, J.X. Assessing the remotely sensed Drought Severity Index for agricultural drought monitoring and impact analysis in North China. Ecol. Indic. 2016, 63, 296-309. [CrossRef]

41. Guo, H.; Zhang, X.M.; Lian, F.; Gao, Y.; Lin, D.G.; Wang, J.A. Drought Risk Assessment Based on Vulnerability Surfaces: A Case Study of Maize. Sustainability 2016, 8, 813. [CrossRef]

42. Chen, J.F.; Deng, M.H.; XIa, L.; Wang, H.M. Risk Assessment of Drought, Based on IDM-VFS in the Nanpan River Basin, Yunnan Province, China. Sustainability 2017, 9, 1124. [CrossRef]

43. Zeng, Z.Q.; Wu, W.X.; Li, Z.L.; Zhou, Y.; Huang, H. Quantitative Assessment of Agricultural Drought Risk in Southeast Gansu Province, Northwest China. Sustainability 2019, 11, 5533. [CrossRef]

44. Zarafshani, K.; Sharafi, L.; Azadi, H.; Hosseininia, G.; De Maeyer, P.; Witlox, F. Drought vulnerability assessment: The case of wheat farmers in Western Iran. Glob. Planet. Chang. 2012, 98-99, 122-130. [CrossRef]

45. Wu, J.J.; Geng, G.P. Global vulnerability to agricultural drought and its spatial characteristics. Sci. Sin. 2017, 47, 910-920. [CrossRef]

46. Bahareh Kamali, K.C.A.; Bernhard, W.; Yang, H. A Quantitative Analysis of Socio-Economic Determinants Influencing Crop Drought Vulnerability in Sub-Saharan Africa. Sustainability 2019, 11, 6135. [CrossRef]

47. Dai, Y.Q.; Wang, L.G.; Hu, B. Agricultural Drought Vulnerability Evaluation of Gansu Province. J. Appl. Sci. Electron. Inf. Eng. 2018, 36, 515-523.

48. Huang, L.M. Vulnerability Assessment of Agricultural Drought in Guizhou Province. Master's Thesis, Guizhou Normal University, Guiyang, China, 2017.

49. Ji, C.R. Research on the Vulnerability Assessment of Agricultural Drought Disaster in Henan Province; Henan University: Kaifeng, China, 2013.

50. Li, M.N. Evaluation of agricultural vulnerability to drought in Guanzhong Area. Resour. Sci. 2016, 38, $166-174$.

51. Pei, W.; Fu, Q.; Liu, D.; Li, T.-X.; Cheng, K. Assessing agricultural drought vulnerability in the Sanjiang Plain based on an improved projection pursuit model. Nat. Hazards 2016, 82, 683-701. [CrossRef]

52. National Bureau of Statistics. Available online: http:/ / www.stats.gov.cn/ (accessed on 17 July 2020).

53. China Meteorological Data Network. Available online: http:/ / data.cma.cn/ (accessed on 28 July 2020). 
54. Sun, R.; Liu, G.D.; Wang, C.D.; Zheng, S. Application of Combination Weighting Method to Agricultural Drought Vulnerability Assessment and Regionalization. Environ. Sci. Technol. 2015, 38, 374-378.

55. Wu, L.; Feng, L.P.; Li, Y.Z.; Wang, J.; Wu, L.H. A Yield-Related Agricultural Drought Index Reveals Spatio-Temporal Characteristics of Droughts in Southwestern China. Sustainability 2019, 11, 714. [CrossRef]

56. Xu, D.M.; Li, P.Y.; Wang, W.C.; Yin, P.B. Analysis on Vulnerability of Agricultural Drought Disaster Based on the Improved Grey Clustering Method. J. Irrig. Drain. 2016, 35, 87-91.

57. Ma, Y.L.; Guo, J.P.; Luan, Q.; Liu, W.P. Assessment of Agricultural Drought Vulnerability in Agro-Pastoral Ecotone in Northern Shanxi Province. J. Catastrophol. 2020, 35, 75-81.

58. Xie, J.Z.; Che, S.F.; Lin, Y. Vulnerabilidy Assessment and the Driving Force in the Management of Agricultultural Drought Hazard. J. Southwest Univ. 2017, 43, 03.

59. Wu, D.; Yan, D.H.; Yang, G.Y.; Wang, X.G.; Xiao, W.H.; Zhang, H.T. Assessment on agricultural drought vulnerability in the Yellow River basin based on a fuzzy clustering iterative model. Nat. Hazards 2013, 67, 919-936. [CrossRef]

60. Zhao, H.J.; Yu, F.W. Evaluation of Agricultural Green Development Level in Main Grain Producing Areas based on Entropy Method. Reform 2019, 11, 136-146.

61. Guo, H.; Xu, S.; Pan, C. Measurement of the Spatial Complexity and Its Influencing Factors of Agricultural Green Development in China. Sustainability 2020, 12, 9259. [CrossRef]

62. Xu, Y. Research and Application of K_means Algorithm and Swarm Intelligence Algorithm(PSO)Fusion. Master's Thesis, Inner Mongolia Agricultural University, Hohhot, China, 2019.

63. Guan, S.; Tang, G. The Research of the Drought Loss Prediction of Distribution and Coping Strategies in China; Yunnan University: Kunming, China, 2015.

64. Yang, Z.; Liu, Y. Spatiotemporal variation of drought in China from 1950 to 2010. In Proceedings of the Research on Water Governance and Sustainable Development in China, Kunming, Yunnan, China, 1-10 August 2012.

65. Zhou, J. Drought characteristics and economic loss assessment in China. J. Catastrophol. 1993, 3, 45-49.

66. Wang, Y.; Zhao, W.; Zhang, Q.; Yao, Y.-B. Characteristics of drought vulnerability for maize in the eastern part of Northwest China. Sci. Rep. 2019, 9, 964. [CrossRef]

67. Du, X.; Huang, S. Comprehensive assessment and zoning of vulnerability to agricultural drought in Tianjin. Nat. Disasters 2010, $19,138-145$. 